\title{
LOS NOMBRES DEL TUBÉRCULO PAPA EN EL QUECHUA DE PAMPACORRAL: HACIA UN ENFOQUE COGNITIVO EN EL PROCESO DE NOMINACIÓN
}

\author{
Frank Joseph Domínguez Chenguayen \\ Universidad Tecnológica del Perú \\ c19138@utp.edu.pe
}

Recibido: 14/02/2020 - Aprobado: 14/04/2020

DOI: doi.org/10.17533/udea.lyl.n78a11

\begin{abstract}
Resumen: Se estudió la manera en la que los quechuahablantes de Pampacorral asignan formas o significantes a diversas especies nativas de papas. Para ello, se analizó el proceso de nominación, donde se integraron una serie de principios teóricos de la lingüística cognitiva. A partir de ello, se logró establecer cómo diversos modelos cognitivos recuperan, inicialmente, información sensorial de los tubérculos y dan origen, posteriormente, a una serie diversa de denominaciones. De esta manera, los nombres de las variedades de papa ponen al descubierto no solo aspectos lingüísticos e históricos, sino también distintos procesos mentales en su construcción.
\end{abstract}

Palabras clave: fitónimos; tubérculo papa; lingüística cognitiva; quechua.

\section{THE NAMES OF THE POTATO TUBER IN THE QUECHUA OF PAMPACORRAL: TOWARDS A COGNITIVE APPROACH IN THE NOMINATION PROCESS}

\begin{abstract}
The way in which Quechua speakers of Pampacorral assign forms or signifiers to various native species of potatoes was studied. For this, the nomination process was analyzed, in which a series of theoretical principles of cognitive linguistics were integrated. From this, it was possible to establish how different cognitive models recover, initially, sensory information of the tubers and give rise, later, to a diverse series of denominations. In this way, the names of the potato varieties reveal not only linguistic and historical aspects, but also different mental processes in their construction.
\end{abstract}

Key words: plant names; potato tuber; cognitive linguistics; Quechua.

LINGÜÍSTICA Y LITERATURA

ISSN 0120-5587

E-ISSN 2422-3174

N. ${ }^{\circ} 78,2020269-296$ 


\section{Introducción}

$\mathrm{E}$ n el mundo andino, el cultivo de la papa presenta una serie de relaciones complejas, pero significativas para estas sociedades y culturas. Las diferentes especies son el resultado de la interrelación entre el hombre de los Andes y su medio; específicamente, entre él y la tierra, entendida esta como una divinidad (en quechua, pachamama «la madre tierra»). Además de constituir un recurso alimenticio importante, el cultivo de la papa representa también una práctica cultural milenaria que se ha transmitido de generación en generación en las comunidades, por lo cual reúne y refuerza lazos o relaciones de parentezco entre las personas que la practican mediante el trabajo comunal. En esta línea, Sánchez Garrafa (2011) señaló que este tipo de cultivos ancestrales se «perciben como seres vivos, que se comportan como personas y que se adsqcriben al ayllu o familia que los acoge en una práctica de mutua crianza y complementación» (p. 26). Pero, como añadió el mismo autor, el cultivo de la papa tiene también «un contenido ritual e ideológico» (p. 16). Aunado a ello, el cultivo de la papa genera, en estas sociedades, un vocabulario que evoca el conocimiento ecológico relacionado con el manejo de la siembra, la cosecha, los ciclos biológicos y factores climáticos (Ocampo-Raeder, 2008). Sin embargo, las papas han sido estudiadas, mayormente, como objetos vegetales, mas no como entidades culturales (Sánchez Garrafa, 2011).

En los Andes peruanos, las papas nativas han sido el objeto de estudio de diferentes investigadores en el marco de variadas disciplinas, tales como la botánica (Herrera, 1929; Vargas, 1954; Ochoa, 1955), la biología (Rojas, 2007) o la ingeniería agrónoma (Segura, 2014), cuyas orientaciones han estado enfocadas esencialmente a la generación de germoplasmas (o bancos genéticos), al análisis de la diversidad genética o al desarrollo de las cadenas de valor que poseen estos vegetales, respectivamente. En esta línea, han sido elaborados diversos catálogos de papas nativas peruanas, los cuales han sido promovidos principalmente por programas como el Centro Internacional de la Papa-CIP, y algunas universidades, (como la Universidad Nacional Agraria La Molina). Los intereses de estas iniciativas han radicado en la clasificación y preservación, así como en el mejoramiento y producción de las distintas variedades nativas de papa. Desde el punto de vista lingüístico, sin embargo, existen pocas investigaciones al respecto (Ballón \& Cerrón-Palomino, 2002).

LINGÜÍSTICA Y LITERATURA

ISSN 0120-5587

E-ISSN 2422-3174

N. ${ }^{\circ} 78,2020269-296$ 
En el caso del presente trabajo, se carece de un estudio propiamente lingüístico en la comunidad campesina quechuahablante de Pampacorral. Más específicamente, semántico, donde se integre un estudio de corte etimológico con un modelo lingüístico que ayude a desentrañar, culturalmente, la manera en la que los quechuahablantes de la comunidad nativa categorizan las diversas especies del tubérculo llamado papa y, con ello, el modo sistemático en que esas entidades vegetales de su entorno experiencial inmediato reciben distintas formas lingüísticas $(v$. gr., waka waqra (en español, cuerno vacuno, de vaca), wallata runtu (en español, huevo de ganso), entre otras; véase el corpus). ${ }^{1}$ Por ello, en el seno de la corriente teórica denominada lingüística cognitiva (Lakoff, 1987; Langacker, 1987; Johnson, 1987; entre otros), se desarrolló un enfoque teórico para esclarecer el proceso por el cual los quechuahablantes destinan formas lingüísticas a estas especies nativas de papas, en particular, y, potencialmente, para el estudio cognitivo de otras denominaciones, en general (v. gr., antropónimos, topónimos, etc.).

El principal objetivo consistió en proveer un enfoque cognitivo para explicitar el proceso de categorización de las variedades nativas del tubérculo papa en la comunidad campesina quechuahablante de Pampacorral y, con ello, esclarecer la motivación que se encuentra detrás de sus nombres en el contexto de la comunidad. Específicamente, este trabajo manejó un conjunto de datos sincrónicamente transparentes para ejercitar dicho enfoque. ${ }^{2}$ Con este propósito, este estudio se expondrá de la siguiente manera: En la sección 2, se abordarán los aspectos metodológicos referidos a la obtención de datos y procedimientos de análisis. Después, en la sección 3, se ofrecerá una aproximación teórica nueva en torno al estudio de los nombres en el área andina, en particular. El análisis lingüístico-cognitivo de los nombres de especies nativas de papa se tratará en la sección 4. Por último, se presentarán las conclusiones.

\section{Aspectos metodológicos}

1. Las distintas denominaciones del tubérculo papa en la comunidad campesina quechuahablante de Pampacorral, en particular, y en otras áreas andinas, en general, carecen de una nomenclatura científica (Hancco, Blas, Quispe \& Ugás, 2008; Ballón \& Cerrón-Palomino, 2002).

2. Por nombres sincrónicamente transparentes, se entienden aquellas denominaciones cuyos términos constituyentes son léxicamente identificables en la lengua. En la comunidad campesina de Pampacorral, por ejemplo, la denominación kuchi runtu representa un nombre sincrónicamente transparente, puesto que los términos que la componen son comprensibles en términos de significado. En este caso, los significados de las formas kuchi y runtu son claros: «cerdo»y «testículo», respectivamente. 
Para esclarecer la relación entre la forma linguiística que recibe una especie nativa de papa y el concepto a la que esta forma alude en la comunidad nativa, esto es, para dar cuenta del proceso de nominación, se llevaron a cabo dos actividades. En primer lugar, se adelantó un trabajo de campo para la obtención del corpus. En segundo lugar, se siguieron un conjunto de pasos para el análisis, entre estos, el uso de una aplicación móvil, la identificación de los significados de las formas que componen los nombres del tubérculo, entre otros. En los subapartados que siguen, se detallarán estos procedimientos.

\subsection{Recopilación del corpus}

Los datos fueron recopilados, principalmente, en el mes de noviembre de $2017 .{ }^{3}$ Durante este mes y en el seno de una familia andina en el distrito de Lares, se tuvo acceso a un texto local de especies nativas de papas de Pampacorral, una comunidad campesina quechuahablante situada en el extremo noreste de la microcuenca Trapiche, en la zona alta del valle de Lares (provincia de Calca, departamento de Cusco). ${ }^{4}$ Por ende, el proceso de obtención de estos fitónimos se basó también en fuentes escritas, $\mathrm{y}$, posteriormente, de un proceso de elicitación.

Además de contar con otros textos en donde aparecen formas lingüísticas quechuas acerca de términos referentes, en general, al tubérculo papa (Godenzzi, 1999; Rojas, 2007; Quispe, 2013), se contó con el material comunal in situ de la comunidad campesina quechuahablante de Pampacorral (Hancco, Blas, Quispe \& Ugás, 2008). En este texto, patrimonio de su agrobiodiversidad, se ofrece un registro de las especies nativas de papas cultivadas en su sociedad junto a sus imágenes. En el marco de este trabajo de campo, el material posibilitó un primer acercamiento a sus fitónimos. Sin embargo, este primer contacto con los datos fue complementado con un proceso de elicitación, tanto para obtener formas lingüísticas correctas $(i$. e., transcripciones ortográficas elicitadas de primera mano), así como para rescatar aspectos

3. Para recoger y corroborar datos, se hizo tres viajes al distrito de Lares. Los dos últimos se efectuaron durante los meses de junio de 2018 y setiembre de 2019, pero el corpus fue elaborado, especialmente, en el 2017.

4. La zona de Pampacorral constituye, actualmente, un área de reserva natural. El distrito de Lares cuenta con

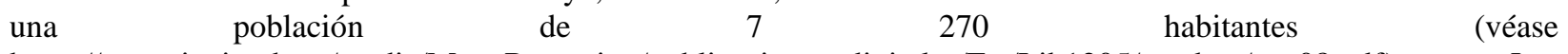
https://www.inei.gob.pe/media/MenuRecursivo/publicaciones_digitales/Est/Lib1205/cuadros/cap08.pdf). Las personas en estas localidades son bilingües, hablantes de español y quechua, y se dedican, por lo general, a la agricultura.

LINGÜÍSTICA Y LITERATURA 
extralingüísticos, tales como las propiedades o características de los tubérculos, el uso que la comunidad hacía de ellos en su sociedad, la cosmovisión, entre otros conocimientos enciclopédicos asociados a estos vegetales.

Como aseguraron Chelliah y Reuse (2011, p. 311), un proceso de elicitación ocurre desde que el investigador induce de alguna manera a que el hablante produzca cierto tipo de dato requerido por este. En esta línea, dos colaboradores hombres y dos colaboradores mujeres fueron inducidos a realizar, fonéticamente, un estímulo visual. ${ }^{5}$ En este caso, mediante el empleo de un procedimiento que los referidos autores denominan como pictorial stimulus-driven elicitation (en español, elicitación mediante estímulos ilustrados) (p. 369), los colaboradores proveían las formas lingüísticas para las imágenes de las especies de papas nativas por las cuales se les preguntaban y que figuran en el texto comunal inicialmente provisto. ${ }^{6}$ Adicionalmente, se obtuvieron los posibles significados de estos nombres de papas, sus características o propiedades, pero también las posibles motivaciones culturales para su denominación. Todo este proceso fue registrado, cuando era necesario, por medio de una anotación escrita y, en todo momento, mediante el uso de una grabadora Sony ICD-PX312. Producto de este trabajo, se recolectaron un total de veintiún nombres de especies nativas del tubérculo papa de la mencionada comunidad. En la tabla siguiente, se muestra el total nombres analizados en este artículo.

\section{Nombres de especies nativas del tubérculo papa en la comunidad de Pampacorral}

\begin{tabular}{lll}
\hline 1. Alqa buli & 2. Kuchi runtu & 3. Kuntur runtu \\
Veteado bola, & Cerdo testículo & Cóndor huevo \\
«bola veteada» & «testículo de cerdo» & «huevo de cóndor» \\
\hline 4. Maqtillu & 5. Miski panti & 6. Muru puma maki \\
Jovencito & Dulce panti (flor) & Moteado puma pata \\
«jovencito» & «panti dulce» & «garra de puma moteada» \\
\hline
\end{tabular}

5. Tres son los elementos comunes en el perfil sociolingǘstico de estos cuatro colaboradores: el lugar de nacimiento y residencia en el distrito de Lares, el nivel nativo de la lengua objeto de estudio (el quechua) y un bilingüismo quechua-español. Respecto de las edades y ocupaciones, las mujeres tenían 46 y 48 , y sus ocupaciones se ceñían a las actividades domésticas del hogar y a la cosecha. Respecto de los hombres, estos tenían 51 y 55 años, y sus actividades se ceñían a la siembra y cosecha, así como al pastoreo del ganado.

6. Las diferentes ilustraciones se encuentran disponibles en el mencionado material (véase las referencias bibliográficas). 


\begin{tabular}{|c|c|c|}
\hline 7. Ñawpaq yuraq k'usi & 8. Pirwanita & 9. Puka ambrosio \\
\hline $\begin{array}{ll}\text { Antiguo } & \text { blanco } \\
\text { calabacín } & \\
\text { «calabacín } & \text { antiguo } \\
\text { blanco» } & \end{array}$ & $\begin{array}{l}\text { Peruanita } \\
\text { «peruanita» }\end{array}$ & $\begin{array}{l}\text { Rojo Ambrosio (antropónimo) } \\
\text { «Ambrosio rojo» }\end{array}$ \\
\hline $\begin{array}{l}\text { 10. Puka kuchi aka-cha } \\
\text { Rojo cerdo excremento- } \\
\text { DIM } \\
\text { «pequeño excremento } \\
\text { rojo del cerdo» }\end{array}$ & $\begin{array}{l}\text { 11. Puka qachun waqa- } \\
\text { chi-q } \\
\text { Rojo nuera llorar-CAUS- } \\
\text { AG } \\
\text { «la roja que hace llorar a } \\
\text { la nuera» }\end{array}$ & $\begin{array}{l}\text { 12. Quwi sullu } \\
\text { Cuy feto } \\
\text { «feto de cuy» }\end{array}$ \\
\hline $\begin{array}{l}\text { 13. Uqi kuchi aka-cha } \\
\text { Plomizo cerdo } \\
\text { excremento-DIM } \\
\text { «pequeño excremento } \\
\text { plomizo del cerdo» }\end{array}$ & $\begin{array}{l}\text { 14. Uqi ñawpaq runtu } \\
\text { Plomizo antiguo huevo } \\
\text { «huevo antiguo plomizo» }\end{array}$ & $\begin{array}{l}\text { 15. Waka waqra } \\
\text { Vaca cuerno } \\
\text { «cuerno vacuno, de vaca» }\end{array}$ \\
\hline $\begin{array}{l}\text { 16. Yana buli } \\
\text { Negro bola } \\
\text { «bola negra» }\end{array}$ & $\begin{array}{l}\text { 17. Yana llama sinqa } \\
\text { Negro llama nariz } \\
\text { «nariz negra de llama» }\end{array}$ & $\begin{array}{l}\text { 18. Yana puma maki } \\
\text { Negro puma pata } \\
\text { «garra de puma negra» }\end{array}$ \\
\hline $\begin{array}{l}\text { 19. Yana qachun waqa- } \\
\text { chi-q } \\
\text { Negro nuera llorar- } \\
\text { CAUS-AG } \\
\text { «la negra que hace llorar } \\
\text { a la nuera» }\end{array}$ & $\begin{array}{l}\text { 20. Yura buli } \\
\text { Blanco bola } \\
\text { «bola blanca» }\end{array}$ & $\begin{array}{l}\text { 21. Yuraq ñawpaq k’usi } \\
\text { Blanco antiguo calabacín } \\
\text { «calabacín antiguo blanco» }\end{array}$ \\
\hline
\end{tabular}

Tabla 1. Relación de los nombres del tubérculo papa analizados en el artículo (corpus) ${ }^{7}$

\subsection{Metodología para el análisis}

Aunque los nombres de especies nativas de papas analizadas en este trabajo se estructuran a partir de piezas léxicas o términos todavía de uso común y recurrentes en la comunidad, es decir, que son sincrónicamente transparentes, se conoce que la información lingüística provista por el nativohablante debe siempre pasar por una criba, en este caso, la información relativa a la forma

7. Para glosar los términos que componen las denominaciones de especies nativas de papa, se tuvieron en cuenta las convenciones que plantean las reglas de glosado de Leipzig. El material se encuentra disponible en https://www.eva.mpg.de/lingua/resources/glossing-rules.php 
y al significado de los términos que componen las denominaciones de las especies de papas. Para reducir, en ese sentido, el grado de subjetividad en el análisis etimológico y evitar incurrir posteriormente en motivaciones sesgadas, se cotejaron, en principio, las formas orales obtenidaas con algunas formas escritas documentadas (Godenzzi, 1999; Ballón \& Cerrón-Palomino, 2002). Por otra parte, también se hicieron consultas lexicográficas para una búsqueda y revisión más amplia de los étimos. En esta primera fase, se utilizó la aplicación QichwaDic, un software electrónico abierto y destinado para aparatos móviles con sistema Android. ${ }^{8}$ En una segunda fase, conscientes también de la necesidad del conocimiento enciclopédico del hablante para el análisis del significado — información que también fue adquirida—, se procedió a establecer las motivaciones no solo como un proceso lingüístico, sino también cognitivo. En esta parte, se vinculó el proceso de nominación con facultades cognitivas y se identificó una serie de procesos de conceptualización (entre ellos, patrones metafóricos y metonímicos). Por último, se procedió al análisis de los fitónimos en función de los rasgos más salientes en el proceso de percepción.

\section{Hacia un enfoque cognitivo en el proceso de nominación en el área andina}

A partir de los estudios sobre dialectología y lingüística histórica desarrollados por Parker (1963), Torero (1964) y, posteriormente, por Cerrón-Palomino (1987), el estudio de los nombres en el área andina se ha situado desde una perspectiva de análisis lingüístico con una amplia y bien marcada tradición (Cerrón-Palomino, 2008; Escobar, 2015; Gálvez \& Domínguez Chenguayen, 2015). En este contexto, la onomástica andina ha estado abocada, esencialmente, a tres aspectos: la reconstrucción lingüística de una lengua (Torero, 1986, 1989; Adelaar, 1990), la filiación lingüística de un nombre (Cerrón-Palomino, 2017; Espinoza Apolo, 2019) y la evaluación de desplazamientos idiomáticos (Torero, 1989; Cerrón-Palomino, 2016). ${ }^{9}$ Aunque estos aspectos son relevantes para el estudio de los nombres, el proceso de nominación constituye un fenómeno complejo que, en lo que respecta al papel de la lingüística como ciencia,

8. Esta aplicación alberga, en soporte informático, una gran cantidad de información lexicográfica, la cual permite una búsqueda y recuperación rápida de los significados que expresan las distintas formas que construyen los nombres del tubérculo papa. Esta aplicación puede ser consultada en el siguiente enlace: https://qichwa.net/

9. Respecto de los estudios sobre toponimia quechua, Gálvez \& Domínguez Chenguayen (2015) mencionaron que el interés ha sido también en la filiación lingüística de los nombres o en la reconstrucción lingüística de una lengua a partir de esos nombres. 
no puede restringirse a un enfoque lingüístico centrado en el carácter etimológico e histórico de esos mismos términos. Los nombres no solo son un producto lingüístico e histórico, sino también cognitivo y cultural. En este nuevo marco, por ello, son cuatro los componentes que se desarrollarán, en este apartado, para un estudio lingüístico-cognitivo de los nombres en el área andina, en particular, y para los nombres, en general (Dobrić, 2010; Karpenko \& Gulubenko, 2015).

\subsection{Los nombres como construcciones motivadas de forma y concepto}

A partir de los presupuestos teóricos de la lingüística estructural (Saussure, 1991) y en tanto unidades lingüísticas que expresan una forma y una especie de significado, los nombres suelen caracterizarse como signos lingüísticos. En esta línea, López Trabanco (1996) remarcó, por una parte, que «los nombres son signos lingüísticos convencionales que el hombre aplica, por ejemplo, a las plantas, que en la terminología especializada son identificados con el término de fitónimos» (p. 1). En el terreno de la toponimia andino-peruana, por otra parte, Solís (1997) señaló que el estudio de los topónimos «lo es de signos linguiísticos: de su significante y del significado» (p. 15). ${ }^{10} \mathrm{El}$ problema con esta caracterización, como se alude también en la toponimia española (Trapero, 1995) y aquella otra de investigación quechua (Gálvez \& Domínguez Chenguayen, 2015), reside en que los nombres, en general, no son construcciones arbitrarias, sino motivadas.

De este modo, entender los nombres como construcciones motivadas implica, por un lado, abandonar la representación de estos como signos lingüísticos. En este caso, es menos discutible caracterizarlos, teóricamente, como unidades simbólicas que comprimen, potencialmente, una serie de propiedades sintácticas y morfológicas en el plano de la forma y, semánticas y pragmáticas en el plano del contenido, emparejadas a través de una correspondencia simbólica (Langacker, 2008), como se esquematiza en la siguiente figura:

10. Aunque López Trabanco (1996) y Solís (1997) utilizaron la etiqueta «signo lingüístico» para caracterizar a los nombres de plantas y de lugares (respectivamente), ambos autores enfatizaron también en el carácter motivacional de estos nombres. En este trabajo, sin embargo, se abandonó ese rótulo y las implicancias que ello acarrea (i. e., la arbitrariedad).

LINGÜÍSTICA Y LITERATURA 


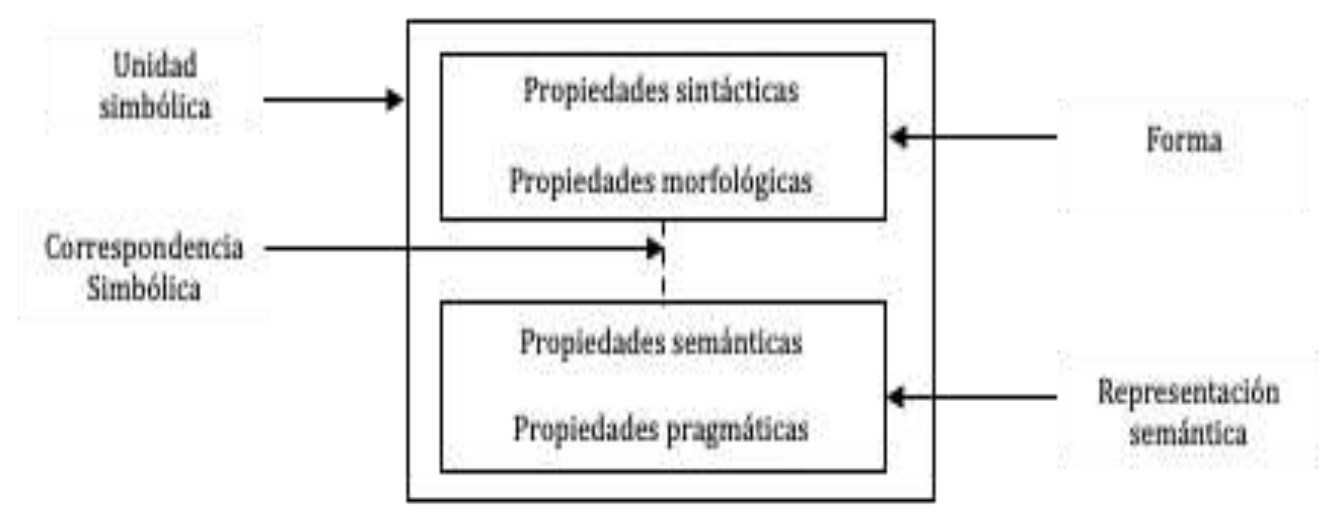

Figura 1. Unidad simbólica. Fuente: Evans (2012).

Concebir que existe una motivación en este tipo de unidades lingüísticas supone, por otro lado, reparar en la correspondencia simbólica que enlaza una forma con una representación semántica. Es decir, poder advertir la manera en la que se construye, por ejemplo, la forma del nombre en relación con el concepto de este. En particular, se entiende la motivación en los nombres como una relación de causa-efecto, donde estos nombres son el resultado de una serie de factores o causas, como lo indicaron Radden y Panther (2004, p. 8). Entre estas causas, según los mismos autores, están aquellas que recurren al sistema lingüístico para guiar parte del proceso motivacional frente a aquellas otras que son independientes del sistema, pero que interactúan con él. En el primer caso, por ejemplo, se mencionarían a aquellas formas o significantes asociados a un nombre como una consecuencia de los significados o conceptos que el hablante intenta transmitir a través del empleo de dichas formas. En el segundo caso, y principalmente, se encuentran los diversos procesos mentales que desencadenan en el hablante y guían el uso ciertas formas sobre otras, tales como la categorización, la percepción, la atención, la conceptualización, entre otros (como se definirán en los siguientes subapartados). Además, Radden y Panther $(2004$, p. 4) se refierieron a estos últimos componentes como factores independientes del sistema (en inglés, language-independent factors). Desde esta perspectiva, la motivación en los nombres, en tanto construcciones de forma y concepto, no solo compromete poner al descubierto los étimos o significados de los términos que componen al nombre (i.e., las causas lingüísticas), sino también, y principalmente, las distintas capacidades cognitivas con las que estos significados interactúan. 


\subsection{El proceso de categorización en el proceso de nominación}

Como ya se mencionó, la motivación en los nombres ha de entenderse como una relación causal. Sin embargo, conviene remarcar que la naturaleza de esta no solo es lingüística, sino también cognitiva. En el marco de este componente, el proceso de categorización tiene relación con el proceso de nominación en tres aspectos.

En primer lugar, el proceso de nominación responde a la necesidad que tiene el hombre de conocer el mundo y las diversas entidades con las cuales este interactúa en él. Sin embargo, como existen innumerables entidades para tratar con ellas individualmente y por separado, una forma de lidiar con todas estas es categorizándolas (Corrigan, 1989). En el proceso de nominación, por lo tanto, se asignan formas a aquellas entidades que constituyen categorías para el hombre (e. .g., personas, animales, plantas, espacios, etc.). De esta forma, se crean antropónimos, zoónimos, fitónimos, topónimos, entre otros. El proceso de categorización constituye, en este primer sentido, una facultad cognitiva base para el nombramiento, puesto que cuando el hombre nombra es porque conoce, y cuando este conoce, es porque categoriza (Harnad, 2005).

En segundo lugar, el proceso de nominación de las entidades no depende del objeto, sino del sujeto y, más exactamente, de cómo este categorice dicho objeto. Para asignarle, por ejemplo, un significante a una entidad vegetal como una papa, es decir, para iniciar un proceso de nominación, el quechuahablante podría evaluar, en principio, la forma. En este caso, podría discriminar si el objeto tiene forma comprimida (como en la variedad runtu «huevo») o forma elíptica (como en la variedad maqtillu «jovencito»), pero podría también incluir aspectos cromáticos en su categorización. En este caso, podría clasificar la entidad vegetal como un objeto con forma comprimida, pero con coloración rojo intermedio y amarillo (como en la variedad pirwanita «peruanita»). El proceso de nominación implica, en este segundo punto, un agente categorizador.

Por último, al enfocar el proceso de nominación como un proceso de categorización, no es realmente necesario originar nuevas categorías para asimilar nueva información. A este respecto, cada vez que se conocen nuevas entidades, no se requiere crear, por completo, nuevos nombres o nuevas formas. Por el contrario, puede llevarse a cabo dicho proceso comparando la información 
recibida del entorno con la información previamente almacenada (Minda \& Smith, 2011). Si se disponemos en quechua, por ejemplo, de la categoría kuchi akacha «pequeño excremento del cerdo» para aquellas papas con forma oblonga y alargada, no se necesita originar nuevos nombres para aquellas entidades con la misma forma y distinto color. En este caso, bastaría para el hablante simplemente especifique el color como un rasgo periférico - como ocurre en uqi kuchi akacha «pequeño excremento plomizo del chancho» y puka kuchi akacha «pequeño excremento rojo del cerdo»—, a partir de un prototipo de categoría — como en kuchi akacha-. De este modo, el proceso de nominación está también sujeto a modelos prototípicos (Rosch, 1978).

\subsection{Los procesos de percepción y atención en el proceso de nominación}

Como se ha visto, el proceso de nominación supone cierta forma de categorización que el sujeto elabora a partir de sus experiencias con el ambiente en el que se desarrolla e interactúa. Estas experiencias, sin embargo, llegan a este a través del cuerpo, de sus propiedades estructurales y de su estructura neuroanatómica, constituyendo así lo que se ha denominado la experiencia corporeizada en el marco de la lingüística cognitiva (Johnson, 1987; Lakoff, 1987; citados por Evans \& Green, 2006). Frente a estas experiencias, los sistemas sensoriales humanos son vitales para construir representaciones del mundo. En este caso, la percepción de las entidades, junto a la atención que generan determinados rasgos en ellas, permite un primer acercamiento a la realidad.

En tanto facultades cognitivas, la atención y la percepción le permiten al hombre fijar un punto de la realidad y extraer información sensorial de ella (e. g., luz, sonido, calor, etc.), que luego este usará como input para un proceso posterior de conceptualización y simbolización de esa misma realidad (sobre estos procesos, véase la sección 3.4.). En este contexto, existen algunas estrategias selectivas de atención que el sujeto utiliza para percibir el mundo, y que aquí se denominan perspectiva y perfilamiento (Verhagen, 2007). La forma quechua runtu (huevo) para ciertas variedades del tubérculo papa, por ejemplo, deviene de la perspectiva que adopta el quechuahablante en la que perfila la estructura oblonga del objeto percibido; mientras que la forma maqtillu captura la estructura elíptica del tubérculo como elemento saliente en la 
perspectiva del hablante. De este modo, la información que ingresa a los sistemas sensoriales es también, y especialmente, significativa para el proceso de nominación.

\subsection{La conceptualización y la simbolización en el proceso de nominación}

En el marco de la linguiística cognitiva, la tesis de la cognición corporeizada (en inglés, embodied cognition thesis) sostiene que no solo las experiencias están corporizadas, sino también los conceptos que se albergan en la mente y que se obtienen a partir de esas mismas experiencias (Johnson, 1987; Lakoff, 1987; citados por Evans \& Green, 2006). En este contexto, se construyen conceptos a partir de la información sensorial que se extraen del entorno (e. $g$., afecto, inteligencia, etc.). En este proceso de conceptualización, la información inicialmente, recibida de los sistemas sensoriales es recuperada conceptualmente, por medio del conocimiento enciclopédico, y reinterpretada mediante diversos mecanismos o modelos cognitivos idealizados (Lakoff, 1987) que desencadenan, posteriormente, en simbolizaciones.

Entre los diversos modelos cognitivos se encuentran, principalmente, pero no exclusivamente, la metáfora y la metonimia (Lakoff \& Johnson, 1980; Lakoff, 1987; Johnson 1987; Croft \& Cruse, 2004). Respecto del proceso de nominación, la metáfora suele ocurrir cuando las formas lingüísticas que instancian un nombre son el resultado de una comparación tácita entre un dominio conceptual fuente y otro dominio denominado meta, — por ejemplo, el nombre del dispositivo mouse en parangón con una estructura semejante a la del roedor-. Por otro lado, el hablante recurre a la metonimia cuando las formas lingüísticas que expresan un nombre evocan una característica del objeto que permite referir al mismo objeto. En este caso, sin embargo, los hablantes no recuperan la información de los organos sensoriales mediante comparaciones, sino mediante referencias, esto es, la denominación de la herramienta destornillador en referencia a su característica principal, que es su función. Como resultado de todo este proceso, ocurre otro de simbolización. En esta última etapa, el sistema lingüístico interviene para asignar forma a un significado o concepto. De allí se desprende que la estructura lingüística está también motivada por la estructura conceptual, es decir, los nombres están también sujetos a procesos de conceptualización). 


\section{Las variedades nativas del tubérculo papa en el quechua de Pampacorral}

En este apartado, se analizará la manera en la que los quechuahablantes de la comunidad campesina de Pampacorral categorizan diversas especies de papas nativas en el seno de su sociedad. Con ello, el modo en que estas entidades vegetales reciben distintas formas lingüísticas queda al descubierto. Como se propuso inicialmente, son siete clases de información sensorial que ingresan al sistema conceptual del hablante para llevar a cabo, posteriormente, un proceso de conceptualización que desemboca en un proceso de nominación.

\subsection{La forma en el proceso de nominación}

En otras localidades, la forma constiuye también un aspecto saliente que le permite al hablante categorizar especies nativas de papa. Para la región de Puno, por ejemplo, existen términos que ponen al descubierto este criterio, tales como platanus papa (en español, papa en forma de plátano), qallu papa (en español, papa en forma de lengua), entre otros fitónimos (Ballón \& Cerrón-Palomino, 2002).

En la comunidad campesina de Pampacorral, un primer ejemplo en el que la forma ingresa al sistema sensorial del quechuahablante reside en la especie nativa denominada waka waqra (en español, cuerno vacuno o de vaca), como se muestra en la siguiente figura:



Figura 2. Waka waqra (en español, cuerno vacuno, de vaca). Imagen adaptada de Hancco, Blas, Quispe y Ugás (2008, p. 65).

Aunque el color de la piel del tubérculo es de carácter negruzco intenso y con coloración secundaria marrón, el hablante centra su atención y perfila, principalmente, su forma alargada, 
con variante falcada, que exhibe dicha variedad de papa en esta primera fase de percepción. En una segunda fase, esta información, inicialmente, recibida de los órganos perceptores, es recuperada a través de un proceso de conceptualización en el que interviene el conocimiento enciclopédico. En dicho proceso, el hablante extrae el conocimiento del dominio conceptual animal, y reinterpreta, metafóricamente, la forma de la entidad vegetal en términos de la forma de la estructura ósea del cuerno del ganado vacuno. Como resultado, ocurre el proceso de simbolización en el que la forma lingüística waka waqra (cuerno vacuno) captura y simboliza los rasgos fenotípicos de esta primera especie de papa nativa.

Otro ejemplo en el que la forma es utilizada en la perspectiva del quechuahablante para categorizar su entorno vegetal reside en el nombre maqtillu (en español, jovencito). Con esta expresión, sin embargo, ya no solo es la forma, entendida como contorno, lo que atrae la atención del hablante, sino también la textura del objeto, como se esquematiza a continuación:

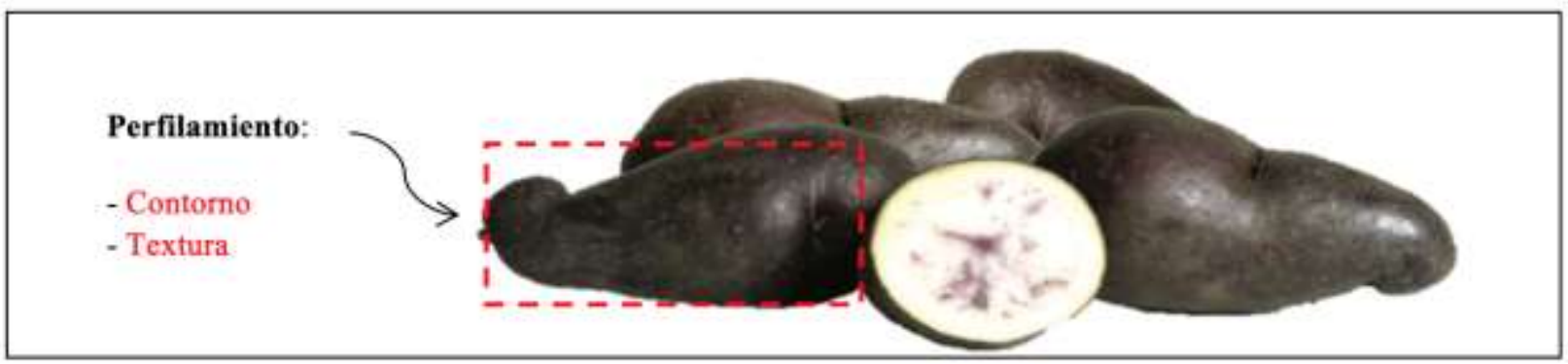

Figura 3. Maqtillu (en español, jovencito). Imagen adaptada de Hancco, Blas, Quispe y Ugás (2008, p. 36).

Así, el sujeto perfila los mencionados atributos de la especie nativa que, en el marco de un proceso de conceptualización, recupera mediante una comparación con el dominio conceptual humano. Según los hablantes, la asignación del nombre de la especie nativa maqtillu (jovencito) se debe al parecido que existe con el órgano sexual del varón; específicamente, con el contorno y textura del aparato reproductor de un hombre joven. Dicho esto, existe un proceso metafórico en el que se compara la imagen de una estructura con la imagen de otra, pero ocurre también un proceso metonímico, puesto que la comparación no es con el sujeto, sino con su órgano sexual. Es decir, para el quechuahablante, la forma lingüística maqtillu (jovencito) evoca metonímicamente el órgano sexual del hombre joven. En tal sentido, se trata de una metonimia 
en la que el hablante accede a una parte a través de un todo, pero que le permite, al mismo tiempo, recoger las características fenotípicas del referido tubérculo.

\subsection{El color en el proceso de nominación}

En algunas otras localidades, existen también indicios lingüísticos que permiten sustentar este criterio como un patrón aislado para el proceso de nominación de las especies de papa. En la región de Puno, por ejemplo, se reportan algunas coloraciones de la papa en azul, rojo, negro, entre otros, como elementos cromáticos salientes (Ballón \& Cerrón-Palomino, 2002). En la comunidad de Pampacorral, sin embargo, se ha hallado únicamente una variedad nativa que reporta, perceptualmente, el color como elemento único categorizador. Se trata de la especie nativa catalogada como pirwanita (en español, peruanita).

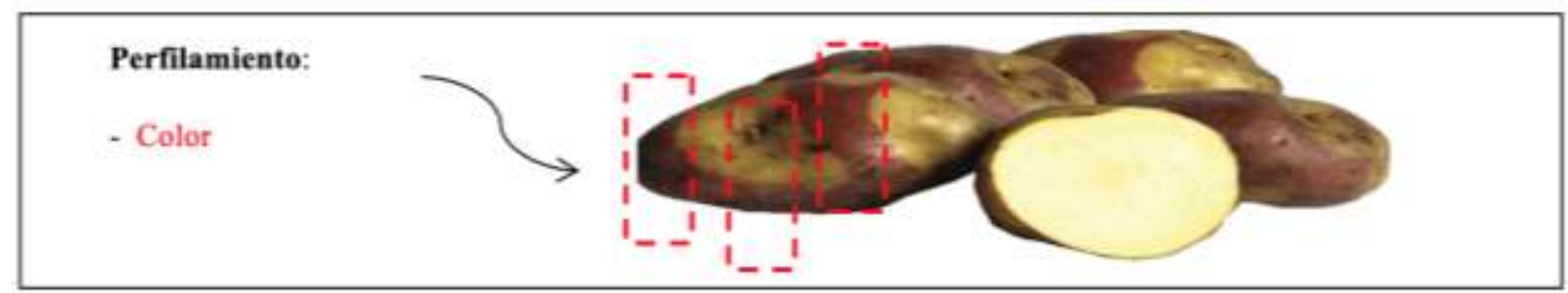

Figura 4. Pirwanita (en español, peruanita). Imagen adaptada de Hancco, Blas, Quispe y Ugás (2008, p. 47).

Al margen de la forma de esta especie, que es comprimida y con ojos profundos, el quechuahablante dirige su atención, principalmente, al color rojo intermedio de la piel o cáscara del tubérculo a modo de franjas, con coloración secundaria en amarillo. Según los hablantes, el nombre de esta especie nativa se debe al parecido que existe con los colores de la bandera peruana, la cual posee dos franjas rojas y una blanca entre estas. Desde esta perspectiva, en el proceso de conceptualización, el hablante retoma estas características a través del dominio conceptual de los objetos, en este caso, por medio de una metáfora, en la que compara el color de la papa percibida con la estructura cromática roja y blanca, que presenta el referido símbolo nacional del Perú. Sin embargo, el hablante utiliza también un procedimiento metonímico. En 
este razonamiento, los colores de la bandera, en asociación con los elementos característicos de la especie nativa, son aludidos metonímicamente por medio del dominio conceptual de la nacionalidad, como se evidencia en la denominación actual del tubérculo, pirwanita (peruanita). De este modo, la especie recibe su denominación.

\subsection{La forma y el color en el proceso de nominación}

Existen especies de papas que ponen en evidencia tanto forma como color en el proceso de categorización. En esta sección, se analizan, a su vez, dos tipos de nombres: a) aquellos que especifican estos rasgos a través de un único referente, y b) aquellos otros que, en la expresión lingüística, especializan un término para alguno de estos rasgos.

En un primer grupo, se encontraron expresiones en las que el referente, en el plano de la conceptualización, contiene ambos atributos de forma y color. Para aquella variedad, al ser oblonga, alargada, con coloración de cáscara rojo-morado intenso y con coloración secundaria amarillo, existe el nombre quwi sullu (en español, feto de cuy).

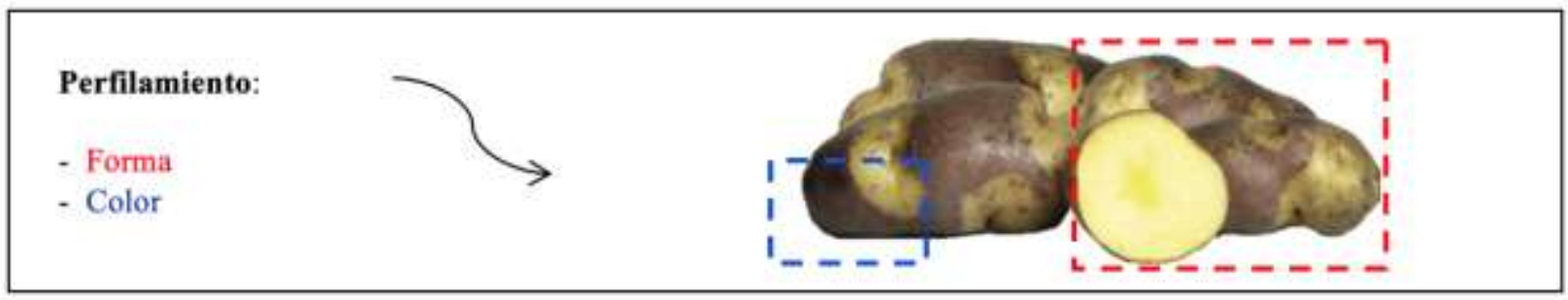

Figura 5. Quwi sullu (en español, feto de cuy). Imagen adaptada de Hancco, Blas, Quispe y Ugás (2008, p. 59).

En el proceso de conceptualización, el hablante emplea un procedimiento metafórico en el que compara la información sensorial saliente del tubérculo con la imagen de forma y color del embrión del mamífero roedor (i. e., el cuy). Como resultado de esta conceptualización, se obtiene la forma quwi sullu.

Otros ejemplos similares en los que la capacidad perceptiva y atencional del hablante toman en cuenta forma y color a partir de una sola imagen que reúne ambos rasgos fenotípicos residen en las expresiones kuchi runtu (en español, testículo de cerdo), wallata runtu (en español, huevo 
de ganso) y kuntur runtu (en español, huevo de condor). En todos estos casos, el conocimiento enciclopédico del hablante evoca imágenes con forma y color para la conceptualización de las entidades vegetales. Las metáforas involucradas, en este caso, comparan diferentes atributos del dominio conceptual vegetal con aquel otro animal (i. e., el cerdo, el ganso y el cóndor). Las referidas formas lingüísticas, por lo tanto, solo expresan estas propiedades fenotípicas que el quechuahablante perfila.

En un segundo grupo, se detectaron expresiones en las que los rasgos de forma y color aparecen de manera especializada. Es decir, en el plano lingüístico, el hablante verbaliza estos atributos por separado. Conviene, a su vez, hacer una distinción lingüística en este segundo grupo.

En una primera subclase, existen categorías en las que la forma ingresa al sistema de la lengua a través de una imagen, cuyo correlato lingüístico es un núcleo simple, es decir, constituido a partir de un único término o pieza léxica. Para aquella variedad de papa, por ejemplo, de color de cáscara negruzco intenso con coloración secundaria marrón en manchas dispersas y con forma oblonga, existe el nombre yana boli (en español, bola negra):



Figura 6. Yana boli (en español, bola negra). Imagen adaptada de Hancco, Blas, Quispe y Ugás (2008, p. 68).

En el proceso de conceptualización, el hablante emplea un procedimiento metafórico para reinterpretar la forma de la entidad vegetal inicialmente percibida, cuyo dominio fuente es el objeto redondo, pero emplea un procedimiento metonímico para caracterizar la estructura cromática de la especie nativa. Ambos procedimientos cognitivos aparecen especializados, respectivamente, en los términos que componen al nombre: en el adjetivo modificador yana (negro) y en el núcleo buli (bola). Algo similar ocurre con otras especies nativas de papas a las 
que los quechuahablantes categorizan a partir de estos mismos procedimientos y en ese mismo orden, tales como alqa buli (en español, bola moteada) y yuraq buli (en español, bola blanca).

En una segunda subclase, existen categorías en las que la forma ingresa al sistema de la lengua a través de una imagen cuyo correlato lingüístico es un núcleo complejo, esto es, que está constituido por dos términos o piezas léxicas. Por ejemplo, para la especie nativa que tiene color de cáscara morado intenso con coloración secundaria marrón y con forma oblonga alargada y con variante de forma concertinado, existe el nombre uqi kuchi akacha (en español, pequeño excremento plomizo del cerdo).

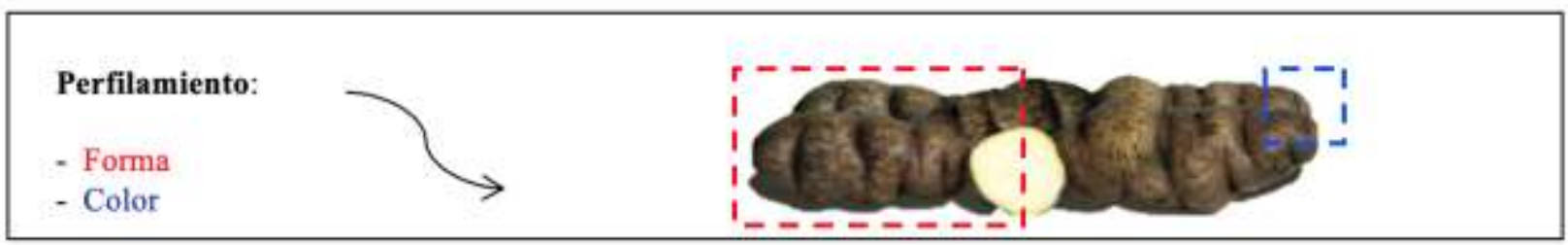

Figura 7. Uqi kuchi akacha (en español, pequeño excremento plomizo del cerdo). Imagen adaptada de Hancco, Blas, Quispe y Ugás (2008, p. 42).

Metafóricamente, la forma ingresa al sistema conceptual del hablante mediante una comparación entre la morfología del tubérculo y la estructura del excremento del mamífero. Metonímicamente, el tubérculo es también definido a partir de su pigmentación. En este caso, mientras la metonimia es rastreable en el término uqi (plomizo), la metáfora, en el compuesto kuchi akacha (pequeño excremento del cerdo). Otros ejemplos que reciben también nombre en el marco de este mismo proceso de conceptualización metáforica y metonímica son las siguientes especies nativas de papas: puka kuchi akacha (en español, pequeño excremento rojo del cerdo), yana puma maki (en español, garra negra del puma), muru puma maki (en español, garra moteada - o con manchas — del puma) y yana llama sinqa (en español, nariz negra de la llama), cuyas imágenes se muestran en la siguiente figura: 


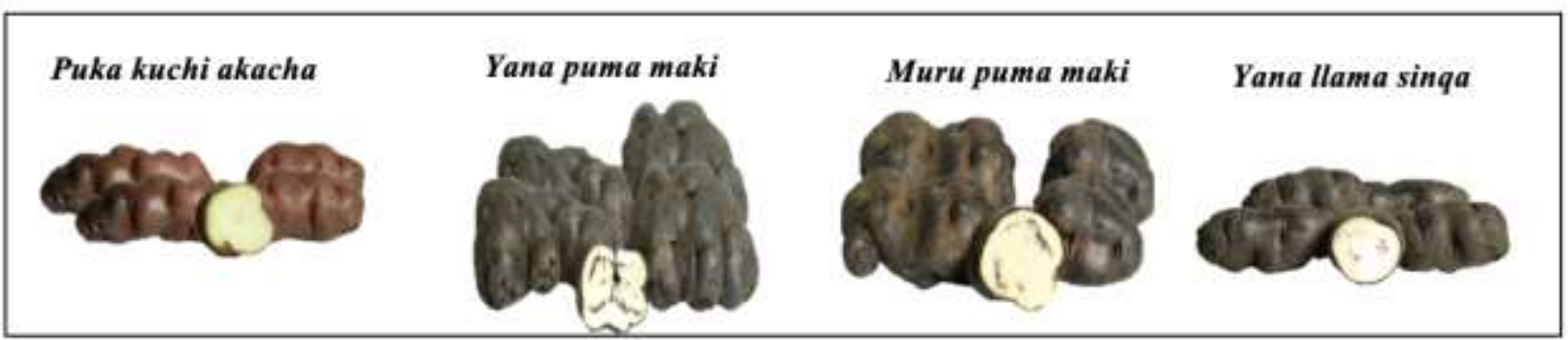

Figura 8. Nombres quechuas para las papas en asociación con algunos animales. Imágenes adaptadas de Hancco, Blas, Quispe y Ugás (2008, p. 50, p. 76, p. 38, p. 72).

En toda esta subclase de fitónimos, la pigmentación se presenta como un rasgo saliente periférico que, en el plano de la lengua, ocurre siempre a la izquierda, como en el caso de puka (rojo), yana (negro) у muru (moteado); mientras la forma, como un rasgo prototípico a la derecha como en kuchi akacha (pequeño excremento de cerdo), puma maki (garra del puma) y llama sinqa (nariz de llama).

\subsection{El sabor en el proceso de nominación}

El sabor como elemento categorizador de las especies de papas nativas aparece también en otras localidades. En la región de Puno, por ejemplo, Ballón y Cerrón-Palomino (2002) reportaron el carácter amargo, picante y rancio para algunas categorías que adquieren denominación a partir de estas características, tales como ruk’i hina (variedad hina amarga), haru pawla (variedad pawla picante) y imilla pasuha (variedad imilla rancia). En la comunidad de Pampacorral, se identificó un único caso, que ha sido catalogado por los hablantes como miski panti (en español, para referirse a una especie de flor denominada «panti dulce»).

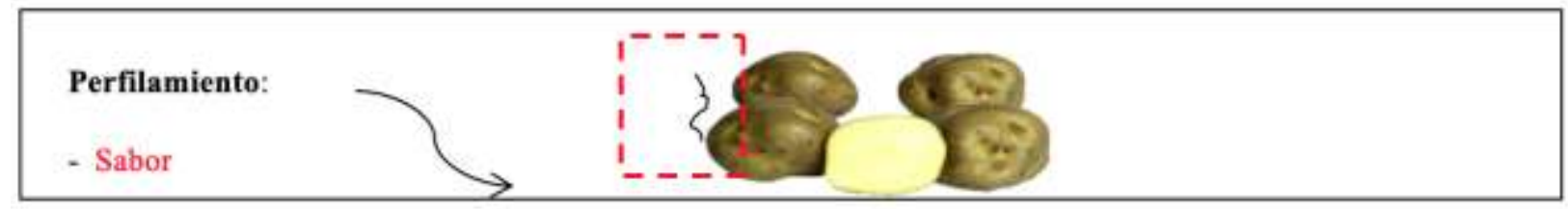

Figura 9. Miski panti (en español, flor panti dulce). Imagen adaptada de Hancco, Blas, Quispe y Ugás (2008, p. 36). 
Miski panti es una especie nativa de papa que se caracteriza por tener una forma comprimida y un color de cáscara amarillo intermedio, pero principalmente por exhibir un sabor dulce al sentido del gusto. En el marco de un proceso de conceptualización, el quechuahablante emplea un proceso metafórico para conceptualizar esas propiedades fenotípicas de forma y color, cuyo dominio fuente es una variedad de hierba medicinal que se le asemeja en forma y color a la papa. Para especificar la variedad de papa, no obstante, el hablante emplea un procedimiento metonímico, por cuanto se refiere al elemento por medio de una característica del elemento, en este caso, el sabor. De este modo, ocurre el proceso de simbolización en el que el nombre refleja, en cierto sentido, la conceptualización.

\subsection{El tiempo de maduración en el proceso de nominación}

En el tiempo de cosecha, existen variedades de papas que alcanzan una madurez más prolongada en comparación con otras variedades que maduran mucho más rápido, es decir, variedades tardías o semitardías frente a variedades precoces. En el registro léxico, por ejemplo, que ofrecen Ballón y Cerrón-Palomino (2002) para la región de Puno, se observan denominaciones que incluyen ambas clases de variedades. En la comunidad campesina de Pampacorral, sin embargo, se han hallado tres fitónimos que evidencian que los quechuahablantes categorizan especies nativas de papa en función, únicamente, de una maduración precoz. En este contexto, existen las especies ñawpaq yuraq k'usi (en español, calabacín blanco antiguo o anticipado), yuraq ñawpaq k’usi (en español, calabacín antiguo o anticipado blanco) y uqi ñawpaq runtu (en español, huevo antiguo o anticipado plomizo).

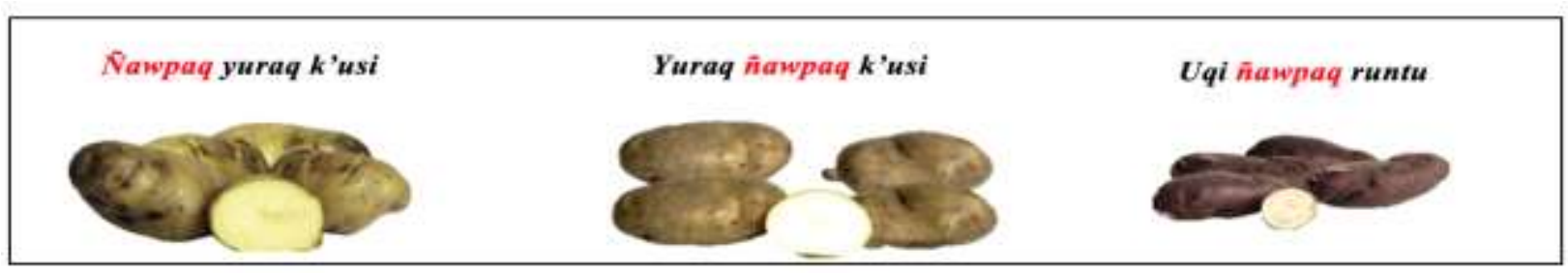

Figura 10. Nombres quechuas para las papas en asociación con su maduración. Imágenes adaptadas de Hancco, Blas, Quispe y Ugás (2008, p. 41, p. 79, p. 43). 
Al margen de la forma de estas especies de papas que también perciben los hablantes, y que se conceptualizan mediante procesos metafóricos distintos - cuyos dominios fuentes son el calabacín o pequeña calabaza cilíndrica y el huevo, respectivamente-, el hablante dirige también su atención hacia el tiempo que tardan en cosechar estas tres variedades, un rasgo común en todas ellas. En el proceso de conceptualización, el hablante emplea un procedimiento metonímico que recupera la información sensorial anterior, y le permite aludir al objeto percibido mediante el tiempo que tarda este objeto en madurar o aflorar. En esta línea, el término ñawpaq (antiguo, anticipado) no es sino la expresión de esta característica de maduración anticipada de este tipo de variedades.

La diferencia entre ñawpaq yuraq k'usi (calabacín blanco antiguo o anticipado) y yuraq ñawpaq k'usi (calabacín antiguo o anticipado blanco) es, sin embargo, una diferencia de capacidad atencional. En el primer caso, el brote del tubérculo es blanco con coloración secundaria morado; mientras que en el segundo, este brote es totalmente blanco, sin ninguna coloración secundaria. Por ende, la redistribución del término yuraq en la estructura lingüística permite capturar esta diferencia perceptual de pigmento en el brote. De manera análoga, el empleo del término uqi (plomizo) en la denominación uqi ñawpaq runtu (huevo antiguo o anticipado plomizo) obedece también a una característica perceptual; en este caso, al color de la cáscara. Sin embargo, en todos estos tubérculos es posible señalar que el hablante no solo atiende y perfila forma y color, como en aquellos fitónimos cuyos componentes expresan estas propiedades, sino también, y principalmente, el tiempo de maduración que, a través de un proceso de conceptualización metonímica, desemboca en las referidas denominaciones que incorporan el ítem léxico ñawpaq (antiguo, anticipado).

\subsection{Personas en el proceso de nominación}

En esta clase, hemos encontrado una variedad nativa que, en la comunidad de Pampacorral, se le cataloga como puka ambrosio (en español, Ambrosio rojo). 
Perfilamiento:

- Color

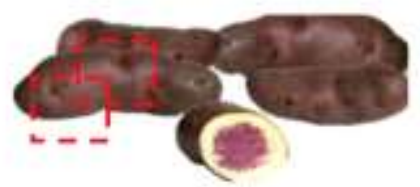

Figura 11. Puka ambrosio (en español, Ambrosio rojo). Imagen adaptada de Hancco, Blas, Quispe y Ugás (2008, p. 48).

La denominación puka (rojo) surge de la percepción del color rojo intenso de la cáscara del tubérculo al que el hablante atiende y al cual se refiere, metonímicamente, es decir, como parte del proceso de conceptualización, el hablante utiliza la característica cromática del objeto percibido para aludir, en parte, a la papa como objeto. La denominación de ambrosio responde, sin embargo, a un evento conmemorativo, en el que el productor de esta especie, Julio Hancco, recuerda a su fallecido sobrino mediante la asignación de su nombre a la entidad vegetal. En este caso, se presenta a una cadena metonímica en la que se alude a una entidad vegetal por medio del nombre de una persona, que, a su vez, alude a un hecho en el que se le conmemora tras su muerte. En la literatura, aunque no se brinda mayor explicación, se reportan también algunas denominaciones para la región de Puno, en las que las papas son referidas a través de antropónimos, e. g., ilsa por Elsa, pawla por Paula, muralis por Morales y yula por Yolanda (Ballón \& Cerrón-Palomino, 2002).

\subsection{El pelado y el color de la cáscara en el proceso de nominación}

En esta última clase, se reconocieron dos subvariedades de papas nativas que se diferencian en relación con el color de la cáscara que los quechuahablantes perciben, pero que pertenecen a una misma categoría respecto de la forma con la que estos hablantes interactúan con ellas. Se trata de la especie nativa qachun waqachiq (en español, la que hace llorar a la nuera), cuyas subvariedades son yana qachun waqachiq (en español, la negra que hace llorar a la nuera) y puka qachun waqachiq (en español, la roja que hace llorar a la nuera): 


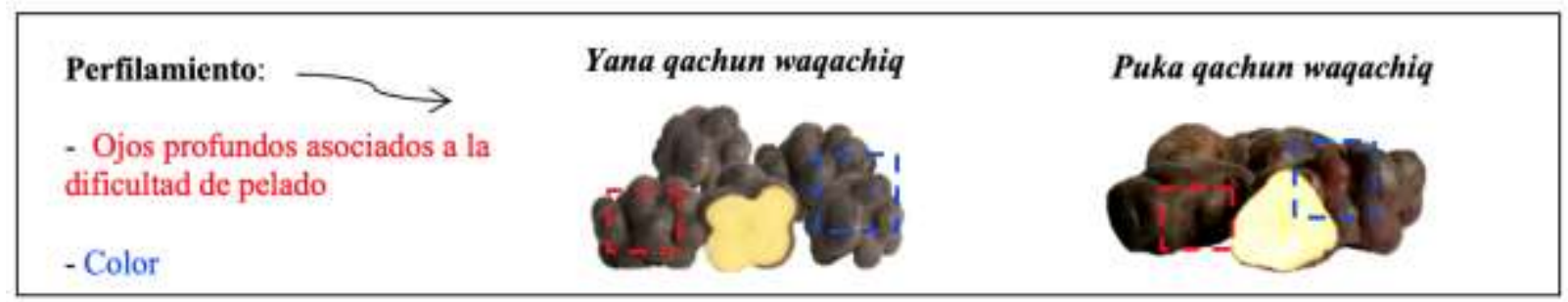

Figura 12. Nombres quechuas de las papas en relación con su dificultad para ser peladas.

Imágenes adaptadas de Hancco, Blas, Quispe y Ugás (2008, p. 71, p. 50).

Según los hablantes, la especie catalogada como qachun waqachiq (la que hace llorar a la nuera) ha sido usada, tradicionalmente, en las comunidades andinas como una prueba en la que los padres del novio evaluaban las habilidades domésticas de la novia como posible integrante de su familia. Sin embargo, por la morfología irregular de la especie nativa, que es oblonga y con ojos o huecos demasiado profundos, este reto suele ocasionarle a las mujeres grandes dificultades para llevar a cabo el pelado del tubérculo en un cierto tiempo establecido. En este contexto, existen dos procedimientos conceptuales que le permiten al quechuahablante recuperar la información sensorial inicial. Por una parte, existe un procedimiento metonímico, por cuanto se utiliza la dificultad del pelado del tubérculo para aludir a dicho tubérculo. Por otra parte, ocurre también un procedimiento metafórico, puesto que el quechuahablante reinterpreta la dificultad en el pelado en términos del llanto o protesta de la futura nuera. La forma qachun waqachiq simboliza, por lo tanto, las percepciones que el hablante genera en esta clase de eventos tradicionales.

Respecto de las subvariedades, los términos yana (negro) y puka (rojo) recogen, lingüísticamente, aspectos periféricos referentes a la estructura cromática de la piel de los tubérculos. En la denominación de estas subespecies, interviene también un proceso metonímico. En este caso, el hablante particulariza al objeto a través de una característica de ese objeto, en este caso, la pigmentación. De este modo, el sistema lingüístico interviene, como en el de la categoría a la que pertenecen, para asignar una forma en consonancia con el concepto generado, como las denominaciones yana qachun waqachiq y puka qachun waqchiq.

\section{Conclusiones}


Como se mostró, la representación teórica de los nombres como signos lingüísticos resulta ser paradójica. Los nombres, por el contrario, se presentan como construcciones motivadas de forma y concepto. Dicho esto, el estudio de los nombres en el área andina puede también enfocarse desde una perspectiva linguiística que no solo atienda, desarrolle y explicite aspectos etimológicos e históricos, como en la onomástica andina, sino también mentales. De acuerdo con ello, el análisis de los nombres debe vincularse también con otras facultades cognitivas, como la categorización, la percepción, la atención, la conceptualización, así como con diversos procedimientos involucrados con estas facultades, tales como la perspectiva, el perfilamiento, la metáfora, etc., que le permiten al hombre aprehender la realidad y, posteriormente, simbolizarla o nominarla.

En un marco cognitivo de la lingüística, el proceso de nominación supone, en principio, un proceso de categorización en consideración con tres etapas o fases: un proceso de percepción y atención, donde el hablante adquiere información sensorial del entorno, un proceso de conceptualización, en el cual esta información sensorial es recuperada y reinterpretada mediante diversos procedimientos, y un proceso de simbolización, a partir del cual la entidad percibida recibe una forma o un significante. Por lo tanto, los nombres, en particular, y el proceso de nominación, en general, no solo son la consecuencia de factores lingüísticos $-\mathrm{o}$ los conceptos que los hablantes pretenden transmitir mediante el empleo de ciertas formas-, sino también, y principalmente, el resultado de una serie de operaciones mentales que gobiernan esta facultad del hombre para asignar o destinar formas a las diversas entidades con las que este interactúa en el seno de su comunidad y su cultura.

Por último, el estudio de los nombres de especies nativas de papas en la comunidad campesina quechuahablante de Pampacorral sigue también este nuevo enfoque lingüístico aplicado, en este caso, a la fitonimia andina. En este proceso de nominación con enfoque cognitivo, se han hallado siete clases de información sensorial que entran en un proceso complejo de conceptualización, el cual desemboca en una serie diversa de formas lingüísticas para las distintas variedades del tubérculo papa en la referida comunidad. Entre esta clase de información sensorial, se han hallado dos fitónimos en los que se perfila la forma (e. g., waka waqra); uno, en cuanto al color (e. g., pirwanita o «peruanita»); once, en cuanto a color y forma (e. g., quwi sullu o «feto de cuy»); uno, en cuanto a sabor (e. g., miski panti o «panti (flor) 
dulce»); tres, en cuanto a tiempo de maduración (e. g., uqi ñaupaq runtu o «huevo antiguo plomizo»); uno, en relación a personas (e. g., puka ambrosio o «Ambrosio (antropónimo) rojo») y dos, en cuanto al pelado y color de la cáscara (e. g., yana qachun waqachiq o «negra que hace llorar a la nuera»). Respecto de los mecanismos cognitivos en el proceso de conceptualización, la metáfora y la metonimia son los mecanismos más recurrentes que estos hablantes emplean.

\section{Referencias bibliográficas}

1. Adelaar, W. (1990). En pos de la lengua culle. En Cerrón-Palomino, R. y Solís Fonseca, G. (Eds.), Temas de lingüística amerindia (pp. 83-105). Lima: CONCYTEC.

2. Ballón, E. \& Cerrón-Palomino, R. (2002). Terminología agraria andina. Nombres quechuamaras de la papa. Cuzco: Centro Internacional de la Papa.

3. Cerrón-Palomino, R. (1987). Lingüística quechua. Cuzco: C.E.R.A. Bartolomé de Las Casas.

4. Cerrón-Palomino, R. (2008). Voces del Ande. Ensayos sobre onomástica andina. Lima: Fondo Editorial de la Pontificia Universidad del Perú.

5. Cerrón-Palomino, R. (2016). El lenguaje como hermenéutica en la comprensión del pasado: a propósito del puquina en la génesis del Imperio Incaico. Diálogo Andino. Revista de Historia, Geografía y Cultura Andina, 49, 11-27.

6. Cerrón-Palomino, R. (2017). Etimología popular y etimología científica: el caso de Atawallpa wallpa para designar al gallo en el mundo andino y amazónico. Lingüística, 33(2), 9-31.

7. Chelliah, S. \& Reuse de, W. (2011). Handbook of Descriptive Linguistic Fieldwork. New York: Springer.

8. Corrigan, R. (1989). Introduction: Linguistic and non-linguistic categorization: Structure and process. En Corrigan, R.; Eckman, F. \& Noonan, M. (Eds.), Linguistics Categorization (pp. 128). Amsterdam: John Benjamins.

9. Croft, W. \& Cruse, A. (2004). Cognitive Linguistics. Cambridge: Cambridge University Press. 10. Dobrić, N. (2010). Theory of Names and Cognitive Linguistics: The Case of the Metaphor. Filozofija i drustvo, 21(1), 135-146.

11. Escobar, E. (2015). La semántica cognitiva y los esquemas-imagen en el sistema fitonímico de los jacaruhablantes. Lengua y Sociedad, 15(2), 35-61. 
12. Espinoza Apolo, M. A. (2019). El onomástico «Quito». Etimología y significado históricocultural. Quito: Universidad Andina Simón Bolívar.

13. Evans, V. (2012). Cognitive Linguistics. Wiley Interdisciplinary Reviews: Cognitive Science, $3(2), 129-141$.

14. Evans, V. \& Green, M. (2006). Cognitive Linguistics: An Introduction. Edimburgo: Edinburgh University Press.

15. Gálvez, I. \& Domínguez Chenguayen, F. J. (2015). Animicidad y agentivización en las construcciones de la toponimia del quechua de Aurahuá-Chupamarca: un enfoque cognitivo. Escritura y Pensamiento, 37, 153-175.

16. Godenzzi, J. (1999). Cognición y lenguas andinas. Apuntes: Revista de Ciencias Sociales, 45, 97-106.

17. Hancco, J., Blas, R., Quispe, M. \& Ugás, J. (2008). Pampacorral. Catálogo de sus papas nativas. Lima: UNALM y ANPE.

18. Harnad, S. (2005). To Cognize is to Categorize: Cognition is Categorization. En Cohen, H. \& Lefebvre, C. (Eds.), Handbook of Categorization in Cognitive Science (pp. 19-43). New York, Elsevier.

19. Herrera, F. (1929). Contribución a la flora del departamento de Cuzco. Revista Universitaria, 57, 66-88.

20. Johnson, M. (1987). The Body in the Mind: The Bodily Basis of Meaning, Imagination, and Reason. Chicago: Chicago University Press.

21. Karpenko, E. \& Golubenko, L. (2015). Problematics of Cognitive Onomastics. Записки 3 ономастики, 18, 285-293.

22. Lakoff, G. (1987). Women, Fire, and Dangerous Things: What Categories Reveal About the Mind. Chicago: University of Chicago Press.

23. Lakoff, G. \& Johnson, M. (1980). Metaphors We Live By. Chicago: University of Chicago Press.

24. Langacker. R. (1987). Foundations of Cognitive Grammar: Volume I Theoretical Prerequisites. Stanford: Stanford University Press.

25. Langacker. R. (2008). Cognitive Grammar: A Basic Introduction. New York: Oxford University Press. 
26. López Trabanco, P. (1996). Catálogo etimológico de las orquideas cubanas. Alcalá de Henares: Servicios de Publicaciones de la Universidad de Alcalá.

27. Minda, J. P. \& Smith, D. (2011). Prototype Models of Categorization: Basic Formulation, Predictions, and Limitations. En Pathos, E. M. \& Wills, A. J. (Eds.), Formal Approaches in Categorization (pp. 40-64). Cambridge: Cambridge University Press.

28. Ocampo-Raeder, C. (2008). Sin culturas nativas no hay papas nativas. La Revista Agraria, 13(97), 13-14.

29. Ochoa, C. (1955). Expedición colector de las papas del norte. Lima: Perú.

30. Parker, G. (1963). La clasificación genética de los dialectos quechuas. Revista del Museo Nacional, XXXII, 241-252.

31. Quispe, N. (2013). Análisis de la cadena de valor de la papa nativa en los distritos de Huayana y Pomacocha, Provincia de Andahuaylas, Apurímac (Tesis de maestría). Pontificia Universidad Católica del Perú, Perú.

32. Radden, G. \& Panther, K. (2004). Introduction: Reflections on Motivation. En Radden, G. \& Panther, K. (Eds.), Studies in Linguistic Motivation (pp. 1-46). Berlín: Mouton de Gruyter.

33. Rojas, P. (2007). Análisis de la diversidad genética de papas nativas (Solanum sec. Petota) de la comunidad de Chahuaytire, integrante del Parque de la Papa (Pisaq-Cusco), y de las papas nativas repatriadas por el Centro Internacional de la Papa usando marcadores microsatélites (Tesis de licenciatura). Universidad Nacional Mayor de San Marcos, Perú.

34. Rosch, E. (1978). Principles of Categorization. En Rosch, E. \& Lloyd, B. (Eds.), Cognition and Categorization (pp. 27-48). New Jersey: Erlbaum Associates.

35. Sánchez Garrafa, R. (2011). Simbolismo y ritualidad en torno a la papa en los Andes. Investigaciones Sociales, 15(27), 15-42.

36. Saussure, F. (1991). Curso de lingüística general. Madrid: Alianza.

37. Segura, B. (2014). Cadena de valor de papas nativas (Solanum andigenum sp.) en la provincia de Jauja, Perú (Tesis doctoral). Universidad Politécnica de Madrid, España.

38. Solís, G. (1997). La gente pasa, los nombres quedan... Introducción a la toponimia. Lima: Herrera Editores.

39. Torero, A. (1964). Los dialectos quechuas. Anales Científicos, 2, 446-478.

LINGÜÍSTICA Y LITERATURA

ISSN 0120-5587

E-ISSN 2422-3174

N. ${ }^{\circ} 78,2020269-296$ 
40. Torero, A. (1986). Deslindes lingüísticos en la costa norte peruana. Revista Andina, 4(2), 523-548.

41. Torero, A. (1989). Áreas toponímicas e idiomas en la sierra norte peruana. Un trabajo de recuperación lingüística. Revista Andina, 13(1), 217-257.

42. Trapero, M. (1995). Para una teoría lingüística de la toponimia (estudios de toponimia canaria). Las Palmas de Gran Canaria: Universidad de Las Palmas de Gran Canaria.

43. Vargas, C. (1954). Las papas sud peruanas. Parte I y II. Cusco: Universidad Nacional San Antonio de Abad.

44. Verhagen, A. (2007). Construal and perspectivization. En Geeraerts, D. \& Cuyckens, H. (Eds.), The Handbook of Cognitive Linguistics (pp. 48-81). Oxford: Oxford University Press. 